\title{
Impact of the Endoscopic Submucosal Dissection on Early Postoperative Outcome after Additional Gastric Resections for Early Gastric Cancer
}

\author{
Jin Sung Kim, M.D., Hong Rae Cho, M.D., Song Su Yang, M.D., Young Chul Im, M.D., Gyu Yeol Kim, M.D. \\ Department of Surgery, Ulsan University Hospital, University of Ulsan College of Medicine, Ulsan, Korea
}

\begin{abstract}
Purpose: The aim of this study was to compare ESD only and subsequent Laparoscopy-assisted gastrectomy (LAG) patients for EGC through propensity score matching analysis.

Methods: This study was a retrospective review of the records of 46 consecutive patients with gastric cancer who underwent LAG after ESD from 2009, September to 2014, September, and propensity matching analysis was performed with 92 patients who underwent LAG without ESD as a control group. Subgroup analysis was performed with the interval of subsequent laparoscopic gastrectomy and endoscopic resection (within 2 weeks, 2 4 weeks, above 4 weeks).

Results: There were no significant differences in age, gender, body mass index, comorbidity, previous abdominal surgery, and location of the lesion or clinical stage between the two groups. Early postoperative outcomes including postoperative complications and postoperative hospital stay were not significantly different between the two groups. According to subgroup analysis with the interval of laparoscopic gastrectomy and endoscopic resection, there were no significant differences in early outcomes in three groups. However, only early postoperative complication rate was significantly higher in patients who received LAG more than 4 weeks after ESD ( 0 versus 4.76 versus 40 per cent; $p=0.0032$ ).

Conclusion: We analyzed the influence of ESD on subsequent LAG using propensity score matching to reduce the bias. However, we found that ESD might induce inflammation for a significant duration, but ESD had little influence on early postoperative outcome of LAG.
\end{abstract}

Received September 14, 2015 Revised October 21, 2015

Accepted October 28, 2015

Corresponding author

Gyu Yeol Kim

Department of Surgery, Ulsan

University Hospital, University of Ulsan College of Medicine, 290-3,

Jeonha-dong, Dong-gu, Ulsan

44033, Korea

Tel: $+82-52-250-7109$

Fax: +82-52-250-8071

E-mail: kimky9107798@gmail.com

Keywords: Early gastric cancer, Subsequent laparoscopic gastrectomy, Endoscopic submucosal dissection, Propensity score matching analysis

This is an Open Access article distributed under the terms of the Creative Commons Attribution Non-Commercial License (http:// creativecommons.org/licenses/by-nc/4.0/) which permits unrestricted non-commercial use, distribution, and reproduction in any medium, provided the original work is properly cited.

Copyright $\odot 2016$ The Journal of Minimally Invasive Surgery. All rights reserved.

\section{INTRODUCTION}

Gastric cancer is still a major health problem and leading cause of cancer death in spite of decreasing worldwide incidence. Especially, Korea and Japan have the highest prevalence of gastric cancer in the world. ${ }^{1}$ Endoscopic mucosal resection (EMR) of early gastric cancer (EGC) without any risk of lymph node metastasis was developed in Japan in the 1980s, and it has been one of the standard treatments of EGC for nearly 20 years. The endoscopic submucosal dissection (ESD), was developed in the late 1990s, which made it possible to remove a large lesion en bloc. ${ }^{2}$ However, because an accurate pathological diagnosis is possible only after total resection of the lesion, some lesions may be judged to have undergone noncurative resection on the basis of the risk of lymph node metastasis. Therefore, lesions presenting with pathological 
risk factors for metastasis, such as lymphovascular infiltration, deep submucosal invasion, and positive surgical margins, should undergo gastrectomy with lymph node dissection. ${ }^{3-5}$

Gastric ulcers artificially created by endoscopic submucosal dissection (ESD) would heal within 8 weeks regardless of size and location. ${ }^{6}$ Fibrosis and wall thickening were observed from 2 weeks after ESD, but regenerative mucosa was not observed until 5 weeks. Even the mucosal defect has been reported that last more than eight weeks. The inflammation and adhesion caused by endoscopic resection might increase the difficulty of the subsequent LAG and the risk of complications, but few retrospective study of additional gastrectomy after noncurative ESD showed that the preceding ESD had almost no influence on changing the gastric resection of the additional surgery. ${ }^{8,9}$

This study compared with propensity score matching surgical data and postoperative outcomes in patients who had LAG after endoscopic resection with those of patients undergoing LAG without previous endoscopic resection.

\section{MATERIALS AND METHODS}

We retrospectively evaluated 566 patients who were underwent elective LAG for gastric cancer at Our Hospital from 2009, September to 2014, September. If we have an emergency surgery due to bleeding or perforation occurred after the implementation of ESD were excluded from the study. Because of the purpose of our study wanted to know about the impact of ESD before laparoscopic gastrectomy. We studied 46 gastric cancer patients who underwent LAG following ESD and 92 gastric cancer patients as control group. Reasons for subsequent LAG were: submucosal tumor invasion (23 patients), poorly differentiation tumor (8), signet ring cell carcinoma (3), lymphovascular invasion (1), and residual tumor (11). The control group did not have ESD before LAG and they were matched through propensity score matching analysis. Propensity score matching was carried out based on age, gender, BMI, type of surgery, location and TNM staging of the disease.

Clinicopathological and surgical outcome data were compared between the two groups. Preoperative clinical data obtained included age, gender, body mass index, preoperative co-morbidity, tumor location and clinical stage. Operative data included duration of operation, degree of lymph node dissection, type of surgery and conversion to open surgery. Pathological data included depth of tumor invasion, number of harvested lymph nodes, and presence or absence of

Table 1. Demographic and tumor characteristics of patients who did or did not undergo endoscopic resection

\begin{tabular}{|c|c|c|c|}
\hline & $\begin{array}{l}\text { With endoscopic resection } \\
\qquad(\mathrm{n}=46)\end{array}$ & $\begin{array}{l}\text { Without endoscopic resection } \\
\qquad(\mathrm{n}=92)\end{array}$ & $p$ value $^{\dagger}$ \\
\hline Age (years) * & $58.9(8.9)$ & $59.4(10.9)$ & 0.77 \\
\hline Sex & & & 0.79 \\
\hline Male & 31 (67.39) & $64(69.57)$ & \\
\hline Female & $15(32.61)$ & $28(30.43)$ & \\
\hline Body mass index $\left(\mathrm{kg} / \mathrm{m}^{2}\right)^{*}$ & $23.7(3.5)$ & $24.2(3.1)$ & 0.45 \\
\hline Co-mobidity ${ }^{\ddagger}$ & $21(45.65)$ & 47 (51.09) & 0.55 \\
\hline Previous abdominal -operation history & $8(17.39)$ & 12 (13.04) & 0.49 \\
\hline Location of lesion (third of stomach) & & & 0.42 \\
\hline Upper & $3(6.52)$ & 12 (13.04) & \\
\hline Middle & $10(21.74)$ & $14(15.22)$ & \\
\hline Lower & $33(71.74)$ & 66 (71.74) & \\
\hline Location of lesion & & & 0.35 \\
\hline AW & $15(32.61)$ & $21(22.83)$ & \\
\hline PW & $6(13.04)$ & $20(21.74)$ & \\
\hline $\mathrm{GC}$ & $7(15.22)$ & $20(21.74)$ & \\
\hline LC & 18 (39.13) & $31(33.70)$ & \\
\hline
\end{tabular}

Values in parentheses are percentages unless indicated otherwise ${ }^{*}$ values are mean (s.d.). ${ }^{\dagger}$ Cross-table analysis using $\chi^{2}$ test; ${ }^{\ddagger}$ Co-mobidity: Hypertension, Diabetes Mellitus, Heart disease, Pulmonary disease, etc. $\mathrm{AW}=$ anterior wall; $\mathrm{PW}=$ posterior wall; $\mathrm{GC}=$ greater curvature; $\mathrm{LC}=$ lesser curvature. 
lymph node metastasis. Early postoperative outcome data comprised postoperative complications, including anastomotic leakage, bleeding, wound infection, abdominal infection, pseudoaneurysm. The length of postoperative hospital stay was recorded. We performed subgroup analysis with the interval of laparoscopic gastrectomy and endoscopic resection (within 2 weeks, 2 4 weeks, above 4 weeks). Duration of operation, number of harvested lymph nodes, number of postoperative complications, length of postoperative hospital stay were compared between the three group. SPSS 21.0 (IBM SPSS Inc., Chicago, IL) for statistical analysis was employed for $\chi^{2}$ test and binary logistic regression to analyze the data. The level of signficance was set at $p<0.05$.

\section{RESULTS}

Demographic and lesion characteristics are summarized in Table 1. There were no significant differences in age, gender, body mass index, comorbidity, previous abdominal surgery, location of the lesion or clinical stage between the two groups. Most (71.74 per cent of both group) of the lesions were located in the lower third portion of the stomach.
There were no significant differences in duration of operation and type of surgery between the two groups (Table 2). There was no conversion to open surgery in both groups. In accordance with the higher percentage of tumors in the lower third stomach of patients who did or did not undergo ESD, Laparoscopy-assisted distal gastrectomy with gastroduodenostomy (LADG GD) was performed more frequently (31 [67.39] versus 51 [55.43]). The number of harvested lymph nodes was similar in the both group (26.3 [7.6] versus 25.1 [9.3]; $p=0.43$ ). Lymph node metastasis was not significantly different between the two groups, whereas the ESD group had a higher incidence of submucosal tumor (50 versus 25 per cent; $p=0.0083$ ).

The early postoperative complication rate was similar in the groups with and without ESD (10.87 versus 6.52 per cent; $p=0.231$ ) (Table 3). The most common complication in two groups was wound infection. No patients who needed reoperation were in the two groups. There were no significant differences in the length of postoperative hospital stay between the groups (10.61 4.66 versus 11.75 .17 days; $p=0.23$ ).

Additional gastrectomy was performed at an average of 24.63 days after ESD. To evaluate the effect of the interval

Table 2. Operative and pathological data

\begin{tabular}{|c|c|c|c|}
\hline & $\begin{array}{l}\text { With endoscopic resection } \\
\qquad(\mathrm{n}=46)\end{array}$ & $\begin{array}{l}\text { Without endoscopic resection } \\
\qquad(\mathrm{n}=92)\end{array}$ & $p$ value \\
\hline Duration operation time $(\mathrm{min})^{*}$ & $243.2(56.8)$ & $257.4(57.9)$ & 0.17 \\
\hline Type of surgery & & & 0.35 \\
\hline LADG GD & 31 (67.39) & $51(55.43)$ & \\
\hline LADG GJ & $9(19.57)$ & $26(28.26)$ & \\
\hline LAPG & $0(0)$ & $2(2.17)$ & \\
\hline LATG & $4(8.70)$ & $12(13.04)$ & \\
\hline LAWR & $2(4.35)$ & $1(1.09)$ & \\
\hline No. of harvested lymph nodes* & $26.3(7.6)$ & $25.1(9.3)$ & 0.43 \\
\hline Depth of cancer invasion & & & 0.008 \\
\hline Mucosa & $23(50.00)$ & $67(72.83)$ & \\
\hline Sbumucosa & $23(50.00)$ & $23(25.00)$ & \\
\hline Serosa & $0(0)$ & $2(2.17)$ & \\
\hline Lymph node metastasis & & & 0.2 \\
\hline NO & $46(100)$ & 85 (92.39) & \\
\hline N1 & $0(0)$ & $5(5.43)$ & \\
\hline N2 & $0(0)$ & $2(2.17)$ & \\
\hline
\end{tabular}

Values in parentheses are percentages unless indicated otherwise * values are mean (s.d.). ${ }^{\dagger}$ Cross-table analysis using $\chi^{2}$ test. LADG $=$ Laparoscopyassisted distal gastrectomy; $G D=$ gastroduodenostomy; $G J=$ gastrojejunostomy; $L A P G=$ Laparoscopy-assisted proximal gastrectomy, LATG = Laparoscopy-assisted total gastrectomy; LAWR = Laparoscopy-assisted wedge resection. 
Table 3. Early outcomes

\begin{tabular}{|c|c|c|c|}
\hline & With endoscopic resection $(n=46)$ & Without endoscopic resection $(\mathrm{n}=92)$ & $p$ value ${ }^{\dagger}$ \\
\hline Postoperative & $5(10.87)$ & $6(6.52)$ & 0.37 \\
\hline \multicolumn{4}{|l|}{ Complications } \\
\hline Wound infection & 4 & 3 & \\
\hline Abdominal infection & 1 & 0 & \\
\hline Anastomotic bleeding & 0 & 1 & \\
\hline Anastomotic leakage & 0 & 1 & \\
\hline Pseudoaneurysm & 0 & 1 & \\
\hline Reoperation & 0 & 0 & NA \\
\hline Postoperative hospital stay (days) $^{*}$ & $10.61(4.66)$ & $11.70(5.17)$ & 0.23 \\
\hline
\end{tabular}

Values in parentheses are percentages unless indicated otherwise *values are mean (s.d.). ${ }^{\dagger}$ Cross-table analysis using $\chi^{2}$ test.

Table 4. Early outcomes according to the Interval between ESD and additional gastrectomy

\begin{tabular}{lcccc}
\hline & $<2$ wks & $2 w \sim 4 w$ & $4 w<$ & $p$ value $^{\dagger}$ \\
\hline No. of patients. & 15 & 21 & 10 & \\
\hline Duration oeration time $(\mathrm{min})^{*}$ & $241.3(57.24)$ & $240(55.74)$ & $252.5(63.16)$ & 0.85 \\
\hline No. of harvested lymph nodes & $26.13(8.11)$ & $27.29(7.32)$ & $24.70(7.83)$ & 0.68 \\
\hline No. with postoperative complications & $0(0)$ & $1(4.76)$ & $4(40.0)$ & 0.003 \\
\hline Postoperative hospital stay (days) ${ }^{*}$ & $10.67(3.44)$ & $10.19(5.00)$ & $11.40(5.80)$ & 0.802 \\
\hline
\end{tabular}

Values in parentheses are percentages unless indicated otherwise *values are mean (s.d.). ${ }^{\dagger}$ Cross-table analysis using $\chi^{2}$ test.

between ESD and subsequent surgery on clinical outcome, the 46 patients who were underwent ESD were divided into three groups: 15 patients who received LAG within 2 weeks and 21 patients who underwent LAG more than 2 weeks to 4 weeks after ESD. Another 10 patients who underwent LAG more than 4 weeks. There were no significant differences in duration of operative times, number of harvested lymph nodes, postoperative hospital stay between three groups. The early postoperative complication rate was a significantly higher in patients who received LAG more than 4 weeks after ESD (0 versus 4.76 versus 40 per cent; $p=0.0032$ ) (Table 4).

\section{DISCUSSION}

Endoscopic resection of EGC without any risk of lymph node metastasis was developed in Japan in the 1980s, and it has been one of the standard treatments of EGC. ${ }^{2}$ However, the lesions may be judged to have undergone noncurative resection on the basis of the risk of lymph node metastasis, these lesions should undergo subsequent gastrectomy with lymph node dissection. ${ }^{3-5}$ The inflammation and adhesion caused by endoscopic resection might increase the difficulty of the subsequent LAG and the risk of complications, but few retrospective study of additional gastrectomy after noncurative ESD showed that the preceding ESD had almost no influence on changing the gastric resection of the additional surgery. To reduce selection bias, Rosenbaum and Rubin proposed propensity score methods for balancing the distributions of observed covariates between treatment conditions and, therefore, approximating a situation that is normally achieved through randomization. ${ }^{10}$ Propensity score ensures homogeneity in the baseline distributions of outcomes among the intervention and control groups, and also avoids estimation error caused by selection bias. In the present study, we analyzed retrospective data by propensity score matching to minimized selection bias.

Although several previous study showed that postoperative complications of LAG did not increase significantly in elderly patients with more preoperative co-morbidities, ${ }^{11}$ the old age and preoperative co-morbidities including diabetes and hypertension might indicate a higher risk of postoperative complications. The other study revealed body mass index as the only independent risk factor for postoperative complications. ${ }^{9}$ Thus we did matched the age, body mass index, type 
of surgery, tumor location and TNM stage with propensity score matching to eliminate potential impact on early surgical results. Nevertheless, our study showed that length of postoperative hospital stay and postoperative complications of LAG did not increase significantly in patients with ESD. Inflammation caused by endoscopic resection probably influenced the subsequent lymph node dissection. However, the extent of lymph node dissection and number of harvested lymph nodes were sufficient to achieve cure and for determining pathological lymph node metastasis in both groups. ${ }^{9}$ ESD induced inflammation for significant duration, but the influence of ESD on early postoperative outcome of LAG was little.

Divided into three groups and analyzed the effect of the interval between ESD and subsequent surgery on clinical outcome. Only the incidence of postoperative complications highly appeared in four weeks or more groups. However, most of these complications were simple wound infections. The incidence is also not only five cases in patients with ESD, is judged to be not clinically meaningful findings in considering that there is no such a big difference in hospital stay after surgery.

According to our knowledge, this is the first study using propensity score matching to analyze the impact of ESD on subsequent LAG. However, our study has some limitations. The biochemical laboratory data associated with inflammation caused by ESD did not include. Because the incidence of postoperative complications is too low rate, it was difficult to analyze the influence of endoscopic resection on subsequent LAG.

Although analysis the influence of endoscopic resection on subsequent LAG using propensity score matching to reduce the bias, we found ESD induced inflammation for significant duration, but the influence of ESD on early postoperative outcome of LAG was little.

\section{REFERENCES}

1) Crew KD, Neugut AI. Epidemiology of gastric cancer. World J Gastroenterol 2006;12:354-362.

2) Tanaka M, Ono H, Hasuike N, Takizawa K. Endoscopic submucosal dissection of early gastric cancer. Digestion 2008;77 Suppl 1:23-28.

3) Oda I, Gotoda T, Sasako M, et al. Treatment strategy after noncurative endoscopic resection of early gastric cancer. Br J Surg 2008;95:1495-1500.

4) Kusano C, Iwasaki M, Kaltenbach T, Conlin A, Oda I, Gotoda T. Should elderly patients undergo additional surgery after noncurative endoscopic resection for early gastric cancer? Longterm comparative outcomes. Am J Gastroenterol 2011;106:10641069.

5) Kakushima N, Hagiwara T, Tanaka M, et al. Endoscopic submucosal dissection for early gastric cancer in cases preoperatively contraindicated for endoscopic treatment. United European Gastroenterol J 2013;1:453-460.

6) Kakushima N, Yahagi N, Fujishiro M, et al. The healing process of gastric artificial ulcers after endoscopic submucosal dissection. Dig Endosc 2004;16:327-331

7) Kakushima N, Fujishiro M, Kodashima S, et al. Histopathologic characteristics of gastric ulcers created by endoscopic submucosal dissection. Endoscopy 2006;38(4):412-415.

8) Kawata N, Kakushima N, Tokunaga M, et al. Influence of endoscopic submucosal dissection on additional gastric resections. Gastric Cancer 2015;18(2):339-345.

9) Jiang $X$, Hiki N, Yoshiba H, et al. Laparoscopy-assisted gastrectomy in patients with previous endoscopic resection for early gastric cancer. Br J Surg 2011;98(3):385-390.

10) Rosenbaum PR, Rubin DB. The central role of the propensity score in observational studies for causal effects. Biometrika 1983; 70(1):41-55

11) Tokunaga M, Hiki N, Fukunaga $T$, et al. Does age matter in the indication for laparoscopy-assisted gastrectomy? J Gastrointest Surg 2008;12:1502-1507. 